\title{
Biopolítica, digitalización y porvenir democrático: por qué las gestiones de la COVID-19 confirman un paradigma tecnoeconómico
}

\author{
Biopolitics, Digitisation and Democratic Future: \\ Why the Management of COVID-19 Confirms \\ a Techno-Economic Paradigm
}

JOAN MORRO (UNED)

Artículo recibido: 12 de agosto de 2020

Solicitud de revisión: 26 de febrero de 2021

Artículo aceptado: 27 de marzo de 2021

Morro, Joan (2021). Biopolítica, digitalización y porvenir democrático: por qué las gestiones de la COVID-19 confirman un paradigma tecnoeconómico. Recerca. Revista de Pensament i Análisi, 26(2), pp. 1-23. doi: http://dx.doi.org/10.6035/recerca.4633

Resumen

Las gestiones de la COVID-19 y la llamada «nueva normalidad» han comportado un oportuno debate de ideas sobre el futuro de la soberanía. Dejando de lado la tecnofilia hegemónica y neoliberal, este debate ha generado dos planteamientos excluyentes entre sí a partir de unas controvertidas declaraciones del filósofo Giorgio Agamben, a saber: uno que prevé un horizonte antidemocrático sometido a las nuevas tecnologías y otro que enfatiza el carácter transversal y contradictorio de estas. En este trabajo, recurriendo a la teoría de los paradigmas tecnoeconómicos, expongo críticamente los principales razonamientos del debate y reflexiono sobre el porvenir de la democracia.

Palabras clave: capitalismo, COVID-19, democracia, frontera, paradigma tecnoeconómico, soberanía.

Abstract

The management of COVID-19 and the so-called "new normality" have brought with a timely debate of ideas about the future of sovereignty. Leaving aside hegemonic and neoliberal technophilia, this debate has generated two mutually exclusive approaches based on controversial statements by the philosopher Giorgio Agamben, namely: one that foresees an undemocratic horizon subject to new technologies and another that emphasizes the transversal character and contradictory of these. In this work, by appealing to the theory of tech- 
no-economic paradigms, I critically set out the main reasonings of the debate and I reflect on the future of democracy.

Key Words: border, capitalism, COVID-19, democracy, sovereignty, techno-economic paradigm.

\section{INTRODUCCIÓN}

La pandemia global de la COVID-19 ha venido acompañada de un prolífero debate de ideas sobre el futuro inmediato del ser humano, la soberanía y la democracia. Giorgio Agamben ocupa un puesto relevante en este debate. $\mathrm{Ha}$ sabido presentar de una manera provocadora y fructífera que el principal problema que supone la pandemia no es meramente natural en la teoría ni conlleva una respuesta meramente técnica en la práctica. Entender esta pandemia como una variable inesperada en un campo de posibilidades neutro y cuantificable y que requiere ser conocida, lejos de reflejar una realidad y una subjetividad puras, expresa ya unas disposiciones radicalmente comprometidas; algo que, por cierto, argumentó recientemente en uno de sus trabajos (Agamben, 2019). Asimismo, entiende las actuales gestiones como preocupantes triunfos de la biopolítica.

Además de coherentes con cierta tradición filosófica, estas tesis son lo suficientemente radicales e influyentes para que en el debate de ideas sobre la pandemia uno se posicione con o contra Agamben, con más o menos matices. En este sentido, se ha dicho que lo que los medios españoles han popularizado como «nueva normalidad» apunta a un deterioro de la democracia en favor de un distópico abuso de las nuevas tecnologías. A la vez, también se ha remarcado que estas son ineludibles para el presente y el futuro de la salud democrática. He aquí dos grandes posturas, en absoluto internamente homogéneas, que considero oportuno comentar críticamente a la luz de las gestiones de la COVID-19.

El artículo está estructurado como sigue. Comento, en primer lugar, las tesis de Agamben según las cuales con la pandemia culmina una biopolítica que lleva la soberanía moderna al paroxismo. Seguidamente, las tesis de Byung-Chul Han, quien sostiene que la biopolítica ha cedido a la psicopolítica, emergiendo así una nueva soberanía cuyo epicentro está en China. Después, critico estas tesis desde una interpretación de los paradigmas tecnoeconómicos, apoyándome en observaciones de Joseph Stiglitz y David Harvey sobre el 
capitalismo actual. Finalmente, reflexiono sobre el porvenir de la democracia en el contexto de esta pandemia.

\section{LA «NUEVA NORMALIDAD» COMO CULMEN DE LA BIOPOLÍTICA}

El debate de ideas sobre la COVID-19 comienza a tomar forma con un artículo de Agamben titulado «¿L'invenzione di un'epidemia?», publicado el 26 de febrero de 2020 en el portal digital de Quodlibet (Agamben, 2020a). Entonces tacha de injustificadas las medidas contra la pandemia y se pregunta por el alarmismo social. En virtud de este pretexto, responde que se está amparando una normalidad basada exclusivamente en el estado de excepción. Esta tesis conecta su obra precedente y su ulterior diagnóstico sobre la pandemia y marca la gran dicotomía en cuanto a las posturas advenidas respecto al transcurso y el desenlace de dichas medidas. Si cuestionamos la tecnofilia triunfante desde la revolución digital acaecida a finales de la guerra fría, junto al neoliberal fin de la historia, la radicalidad de este enfoque hace que en el debate de ideas sobre esta crisis uno tenga que estar con o contra Agamben. Cuando las posturas se polarizan es al argumentar la naturaleza y el horizonte de lo que los medios españoles han presentado como «nueva normalidad».

Agamben sostiene que la normalidad advenida responde a dispositivos biopolíticos que se han sofisticado históricamente. Tomando a Michel Foucault, entiende que la esencia de un dispositivo radica en redes estratégicas que ligan el saber técnico y el poder soberano (Agamben, 2011). Asume que el capitalismo no habría triunfado si la vida orgánica no se hubiera incluido en los mecanismos y cálculos de los Estados (Agamben, 1998: 11-12). El estudio pormenorizado del cuerpo humano y sus posibilidades no es algo aislado ni neutral. Por el contrario, responde a una compleja estrategia de dominación sin la cual no se entiende la modernidad. No hay enfoque biológico $-\mathrm{y}$, por extensión, médico y antropológico- que no oculte unos intereses de poder y de subordinación de la conducta humana. Este planteamiento es determinante en su diagnóstico de las gestiones de la COVID-19.

Analizando la situación italiana, Agamben ha sostenido que el estado de excepción como paradigma definitivo de la forma de gobierno y el hecho de que no haya un enfrentamiento firme a las gestiones de la pandemia denotan una situación por la que el pánico colectivo ha devenido una necesidad. A 
su juicio, sendos fenómenos se intensificaron y globalizaron con la guerra contra el terror tras el 11S. Por tales fechas, advertía que «Bush está tratando de crear una situación en que la excepcionalidad se convierte en regla y la distinción entre paz y guerra (y entre guerra exterior y guerra civil mundial) resulta imposible» (Agamben, 2004: 38). Durante la pandemia, ha sintetizado estas dos hipótesis con la idea de contagio, que entiende como la nueva clave para tomar decisiones en el sentido ofrecido por Carl Schmitt (Agamben, 202ob). Comenta que esta idea aparece en el siglo XVI en ciudades italianas afectadas por la peste y que, desde entonces, arraiga con una biopolítica preventiva. El contagio implica que alguien sano es potencialmente un apestado, un indeseable, para lo cual solo hay un remedio: la alianza a priori entre los saberes técnicos sobre la corporalidad humana y el soberano, entendiendo por este, según la célebre fórmula schmittiana, «quien decide el estado de excepción» (Schmitt, 2001: 23). Rastreando la presencia del contagio, sugiere una serie de analogías entre dicha alianza, la lucha antiterrorista y las gestiones de la pandemia actual.

Agamben ha pronosticado la culminación de una situación generalizada de nuda vida amparada por una naciente bioseguridad en que las libertades estarán más limitadas que nunca (Agamben, 2020c, 2020h). Años después de haber remarcado frente a Schmitt que lo que caracteriza la política occidental no es tanto la pareja amigo-enemigo cuanto la de nuda vida-existencia política (Agamben, 1998: 18), en marzo del 2020 ya advertía que la nuda vida es lo único que queda en Italia, pues los italianos están dispuestos a sacrificarlo todo con tal de no enfermarse de coronavirus. También se ha preguntado por qué no ha habido oposición relevante al confinamiento, pese a que ha comportado que seres queridos mueran solos y que sus cuerpos sean incinerados sin funerales, a lo que ha respondido que la peste ya estaba ahí, antes de que se declarara oficialmente el estado de alarma (Agamben, 2o2od). Dice que en esta situación se observa que la población acepta como verdadero lo que sabe que es falso y cómo las iglesias se pliegan para que la ciencia soldada con la técnica devenga «la vera religione» (Agamben, 2020e, 2020g). El resultado es que asumimos reducir nuestra vida a mera biología, lo cual entiende como una transición a la imposición de un tiránico leviatán construido para la salvaguarda de cuerpos aislados y controlados (Agamben, 2020d). Sin evitar la provocación, lanza un símil entre el virólogo y el teólogo, diciendo que ambos dicen cómo debemos 
vivir en nombre de un objeto de estudio que nunca acaban de definir (Agamben, 202of).

Lo que Agamben ha dicho sobre las gestiones de la pandemia encaja en su obra y en una tradición intelectual y académicamente respetada. Nada de esto ha evitado que reciba todo tipo de objeciones. ${ }^{1}$ En cualquier caso, sus tesis presentan observaciones transversales y una hipótesis general que merecen ser pensadas y convertirse en puntos de partida para un debate crítico sobre tales gestiones. En efecto, no se trata de rechazar la ciencia, sino cierta lectura dogmática que obvia redes de pensamiento y acción ciertamente complejas. Agamben ha apelado a valoraciones del CNR (Agamben, 2020a) y ha acusado a periodistas y políticos de carecer de cientificidad e ignorar nociones básicas de epistemología (Agamben, 202of, 2020g). Además, no dice que biólogos y médicos no deban hacer su trabajo y pronunciarse en público, sino que advierte de los riesgos morales y políticos de no cuestionarlos. Esto resulta tan básico que instituciones como Nature han señalado que encontrar una cura para la COVID-19 comporta dilemas éticos, al menos porque la experimentación con humanos sanos es legal (Callaway, 2020).

No es preciso asumir las tesis fuertes del análisis biopolítico para sostener que cualquier gestión debe poder criticarse desde parámetros alternativos a los de las ciencias. Y es que gestiones como las que requiere una pandemia global no dejarán de ser políticas por muy científicas que se adjetiven y por muchos científicos que haya implicados. Debería causar estupor repetir esto después del siglo XX. Asimismo, las gestiones de la COVID-19 están mostrando la necesidad de la filosofía, aun con independencia del enfoque y la tesis que se tomen al respecto. Por ejemplo, desde postulados diferentes al del biopoder, David Harvey ha recuperado la distinción marxista entre primera naturaleza y segunda naturaleza para subrayar que las consecuencias humanas del coronavirus dependen de las grietas y vulnerabilidades del modelo económico hegemónico y cuestiona que los virus sean del todo externos a las estructuras de acumulación de capital (Harvey, 2020, 2021). Me detendré en esto más adelante. Por lo demás, aunque no se acepte la argumentación de Agamben, es legítimo y oportuno preguntarse si las gestiones de esta pandemia están realizándose con el arraigo de un capitalismo sin liberalismo, donde las libertades individuales y los espacios privados parecen ser más vestigios que derechos efectivos.

1 Para una exposición de diversas reacciones a Agamben, véase Matos y García Collado, 2020. 


\section{HACIA UNA SOBERANÍA ILIBERAL}

El enfoque biopolítico de Agamben implica, además de una ética y una filosofía política, una filosofía de la historia. Concretamente, aquella por la que el capitalismo y los procesos de modernización se identifican en una penosa y sofisticada estrategia de dominación. Aunque con matices que comentaré, en este frente del debate de ideas sobre las gestiones de la COVID-19 está ByungChul Han, para quien están mostrando una nueva forma de soberanía. Solo así, sugiere, se entiende la «nueva normalidad».

Han también enmarca su diagnóstico de las gestiones en su obra precedente. Esto le lleva a cuestionar a Agamben y remarcar que, si bien nos encontramos en un punto de inflexión de una historia dramática, no vamos tanto al culmen de la biopolítica cuanto a un paradigma que él identifica con la psicopolítica. Valga decir que años atrás dijo que Foucault se posicionaría con sus tesis y no con las de Agamben (Han, 2014b: 40-41).

La psicopolítica, con ayuda de la vigilancia digital, está en condiciones de leer pensamientos y controlarlos. La vigilancia digital se desprende de la óptica del Big Brother, no fiable, ineficiente, perspectivista. Y es tan eficiente porque carece de perspectiva. La biopolítica no permite ninguna intervención sutil en la dimensión psíquica de los hombres. En cambio, el psicopoder está en condiciones de intervenir en los procesos psicológicos (Han, 2014a: 106).

Han reafirma este diagnóstico en un artículo publicado el 22 de marzo de 2020 en El País intitulado «La emergencia viral y el mundo de mañana» (Han, 2020a). Matizando las tesis de Agamben, advierte que no estamos ante el triunfo definitivo del poder moderno, sino ante el deterioro histórico del liberalismo europeo. La prueba está en que la gestión europea basada en el cierre de espacios, aunque responde a un modelo tradicional de soberanía, no ha conseguido la eficacia en cuanto al control del coronavirus que sí han logrado algunos países asiáticos. China, Japón o Corea del Sur han optado por una gestión centrada en el uso de datos proporcionados por IA y big data. Esto no significa que en estos países no se hayan cerrado espacios y que en Europa se hayan menospreciado los datos. A lo que apunta Han es a subrayar que es en estos países asiáticos donde se está determinando el futuro del poder soberano.

Han sostiene que las gestiones de la COVID-19 muestran una transformación de las fronteras, la cual se ha venido fraguando desde la irrupción de las TIC. Estas han modificado el sentido de frontera. Como dijera Étienne Balibar, 
la frontera en la política moderna es la «institución de instituciones», de ahí que entenderla remita a problemáticas generales que afectan a todo el tejido social (Balibar, 2008: 93). ${ }^{2}$ Pues bien, siguiendo esta estela, uno de los análisis que Han ha seguido desarrollando con la pandemia radica en reconocer qué es una frontera a partir de las enfermedades emblemáticas de la sociedad. En este sentido, lo que las TIC han generado es que las fronteras ya no sean de tipo inmunológico, sino neural (Han, 2015). El principal efecto de este traslado es que las dicotomías decimonónicas, fundamentalmente negativas, tales como nativo/extranjero o nosotros/ellos, se han diluido en datos que se agrupan en función de algoritmos que presumiblemente concentran disposiciones e intenciones hasta tal punto que predicen y condicionan nuestra mente. Una de las principales lecciones de la IA durante la pandemia, según Han, es que hay fronteras ahí donde lo mental aún no está traducido en datos. Y, a su juicio, las gestiones de la COVID-19 están tendiendo a erradicarlas al máximo.

El aspecto fundamental de este nuevo sentido de frontera es la erosión de lo privado y lo público. Lejos de ser pura, esta frontera deriva de los triunfos históricos de la burguesía liberal, la primera clase social de la historia que exigió con éxito liberarse de la política entendida como res publica (Zolo, 1994: 85). La privacidad stricto sensu es un producto moderno que consiste en reservar esferas de acción independientes de la potestad soberana. Han subraya que tales esferas se han diluido con las TIC. Estas nos separan y nos unen de una forma radicalmente nueva, así como nuevas son las fronteras y sus efectos.

Hasta finales de la guerra fría, la normalización pasaba por adaptarse a un objeto, algo ya dado, presupuesto, siempre de acuerdo con los rituales e intereses implicados y oficializados. Las prácticas modernas anteriores a la expansión de las TIC suponen la diferenciación de una esfera pública y otra privada, pero manteniendo una relación interna, dado que ambas se ubican en el interior de las fronteras de un espacio regido por una burguesía reconocida por un concierto internacional de Estados liberales en una perpetuación de la Santa Alianza resultante de las guerras napoleónicas (Zolo, 2000: 29-48). La burocracia moderna se ha encargado de diferenciar política y espacialmente entre formalidad e informalidad, trabajo y familia, consumo y descanso, masculino y femenino, producción y ocio, cultura y entretenimiento, profesionalidad y personalidad, entre otras distinciones correspondientes a lo público y lo

2 Para un análisis de las implicaciones filosóficas de esta idea, véase Morro, 2014. 
privado y, por ende, a los valores burgueses. Estas distinciones se difuminan cuando estos valores decaen. Mientras la frontera entre lo privado y lo público ha normalizado las relaciones sociales, la política liberal ha sido hegemónica, y viceversa. La transformación de dicha frontera, debida a las nuevas tecnologías, comporta el fin de esta hegemonía.

Uno de los ejemplos más repetidos de Han para captar la transformación de las fronteras es el mandato de la transparencia. Este se extiende a toda la población en cualesquiera circunstancias de la mano de las innovaciones tecnológicas y de lo que después concretaré como el paradigma tecnoeconómico vigente. Este mandato surge en la posguerra fría a la par que genera una nueva sociedad, ya que requiere de una alternativa al dominio de las enfermedades inmunológicas heredado del siglo XIX: ahora es inaceptable que pueda haber algo extraño, negativo (Han, 2015: 11, 14). Incluso quienes dicen criticar el capitalismo optan por visibilizar sus causas mediante las TIC. «En lugar de lo público se introduce la publicación de la persona. La esfera pública se convierte con ello en un lugar de exposición» (Han, 2013: 69). Esto no fue producto del triunfo irreversible y definitivo de la democracia liberal y el libre mercado, sino un paso para afianzar una nueva clase capitalista con proyección global y monopolística, la de los gigantes tecnológicos de base siliconiana, tales como Google, Amazon o Facebook. Las TIC reducen todo a datos y, por tanto, a transparencias computables, acumulables, revisables y solubles en algoritmos sobre la psicología humana que, a su vez, repercuten en esta. De hecho, el mandato de la transparencia comporta malestares de tipo neural, lo cual se tiene en cuenta en guías oficiales de gestión clínica de la COVID-19, ${ }^{3}$ y convierte en sospechoso todo lo que no sea traducible en términos como los señalados.

El colofón del artículo de Han es que la gestión china de la COVID-19 muestra que el soberano actual es quien dispone de datos. Hoy, los generamos al clicar desde cualquier dispositivo conectado a Internet. Quien los tenga a su disposición, dice, decidirá sobre el estado de excepción. La razón por la que es en China donde puede reconocerse la nueva soberanía no es porque en Europa se opte por seguir cerrando fronteras contra posibles contagios, siguiendo una medida que Agamben localiza en el siglo XVI, sino porque el mandato de la transparencia ha calado más allí. Y es que las viejas fronteras, las que diferen-

En una guía publicada por la OMS para gestionar clínicamente la pandemia, en fecha tan temprana como mayo del 2020, se señala la presencia del delirio y los posibles síntomas de depresión y ansiedad en quienes padecen este coronavirus (WHO, 2020: 34-37). 
cian entre lo privado y lo público junto con los viejos valores burgueses, allí apenas deben ser derribadas. Apenas existen. Pero, según Han, es cuestión de tiempo que los europeos le compren a los chinos su modelo, por eficaz. Así, el principal horizonte europeo es un capitalismo con más tecnología y menos liberalismo.

\section{UNA CRÍTICA A AGAMBEN Y HAN DESDE LA TEORÍA DE LOS PARADIGMAS TECNOECONÓMICOS}

La principal diferencia entre Agamben y Han en el debate de ideas sobre las gestiones de la COVID-19 radica en qué cabe esperar del futuro de la soberanía. Mientras que para Agamben nos dirigimos hacia un culmen de la biopolítica, comportando un terrorífico panorama, Han advierte un nuevo poder soberano. La expansión del mandato de la transparencia supone la decadencia de los valores burgueses y una oportunidad para que China acabe haciéndose con la hegemonía mundial. No obstante, mostrando menos pesimismo que el italiano, en su artículo sugiere un triple escenario: frente a las gestiones europeas y asiáticas, cabe imaginar una revolución realizada por personas racionales. Frente al tono apocalíptico de Agamben, Han no descarta resistencias personales ante la soberanía psicopolítica.

Pese a las diferencias, Agamben y Han toman de Schmitt la idea de soberanía. La entienden como algo que construye un mundo. En su clásico ensayo sobre el tema, Schmitt dice que «Todo orden deriva de una decisión; y también el concepto del orden jurídico [...] se basa en una decisión y no en una norma» (Schmitt, 2001: 25-26). La decisión política, además de construir las normas de todos los sistemas políticos, así como toda «nueva normalidad», genera la metafísica dominante de cada época (Schmitt, 2001: 49). El soberano decide cómo son las cosas, bien porque decide el estado de excepción, bien porque dispone de los datos. Esta segunda opción es la de Han, por la que se desmarca de Agamben e intenta ser consecuente con el hecho de que Schmitt, en su vejez, se vio tentado a reformular la idea de soberanía a partir de la comercialización masiva de la radio y la televisión; la difusión y el disputado control de ondas electromagnéticas le aterrorizaban (Han, 2014a: 19). Su interpretación supone que el poder soberano es subsidiario de la tecnología. La soberanía no implica una alianza biopolítica inter pares de saber técnico y po- 
der soberano, como sugiere Agamben, sino la redefinición y jerarquización de los poderes en virtud de las exigencias marcadas por las novedades tecnológicas.

Agamben y Han no solo toman su idea de soberanía de Schmitt: como él, suponen que se expande desde el momento en que una decisión aparece milagrosamente. Obvian las contradicciones que la posibilitan; a lo sumo, la enmarcan en dispositivos no menos abstractos. Por decirlo con Christian Laval y Pierre Dardot, asumen con Foucault que el capitalismo responde a una estrategia sin estrategas (Laval y Dardot, 2015: 191-193) y de ahí que pongan en el centro del debate la pregunta de si la soberanía va a remolque o de la mano de los saberes técnicos en lugar de concretar qué es lo que determina que sean correlativos al poder soberano. Se acogen a lo que Schmitt acuñó en 1922 como «decisionismo» (Schmitt, 2001: 41). De acuerdo con esta doctrina, hasta los valores burgueses surgen de una decisión política (Schmitt, 2001: 59-60). Si hay sociedad moderna, con lo que esto implica, es porque así se ha decidido.

Ante la tecnificación del poder y la politización de la técnica, Schmitt apostó por una soberanía pura, acorde con una comunidad orgánica y espiritualmente enraizada en un territorio. No es el caso de nuestros autores. Primero, entienden toda soberanía como la forma genérica que subyace a un dispositivo y que, como tal, anula a las personas. Segundo, tras sus análisis de las gestiones de la pandemia, han apostado expresamente por una salida espiritualizada y personal que poco tiene que ver con una lucha por la soberanía. Proponen que cada cual actúe según su verdad para liberarse, bien del biopoder, bien del psicopoder. Tercero, la tecnofobia integral que comparten les condiciona a identificar apriorísticamente las relaciones entre técnica y poder como algo indeseable. Por lo demás, no explican qué es lo que genera la decisión efectiva, obviando las contradicciones que posibilitan la soberanía.

Agamben y Han soslayan que el saber técnico y el poder soberano son expresión - que no causa, efecto o superestructura- de las relaciones socioeconómicas existentes, con conflictos, estrategas y medios que estos disponen. En el capitalismo, tal expresión comporta lo que, interpretando a Schumpeter, Joseph Stiglitz llama la «competencia por el mercado» en contraposición a la «competencia en el mercado» (Stiglitz, 2015: 12; Stiglitz y Greenwald, 2016: 167). No es que los capitalistas se limiten a competir, sino que destruyen y crean relaciones socioeconómicas buscando su beneficio. Poco antes de la pandemia, Stiglitz declaró que los defensores del neoliberalismo están 
desacreditados por haber alentado al descontrol con presuntas evidencias científicas en lugar de haber propuesto medios democráticos para afrontar esta cuestión histórica (Stiglitz, 2019). Como comentaré después, esta presunta competencia está convirtiendo a los gigantes tecnológicos en auténticas amenazas para la democracia. Si la soberanía y la tecnología van de la mano y la vanguardia de esta segunda opera en gran medida para los beneficios privados, la democratización del poder y el saber no pueden sino estar en riesgo.

En los análisis de Agamben y Han, la nueva clase capitalista está diluida en dispositivos y la economía se entiende como una consecuencia específica de una soberanía abstracta, ignorando la transición en cuestión con sus efectos en los actores sociales. De acuerdo con ambos, el poder soberano que se avecina se reconoce en un despliegue extraordinario de las TIC con el pretexto de la pandemia y el bienestar, pero en este despliegue es preciso destacar la primacía conseguida para el teletrabajo y la educación, el consumo y el ocio online, entre otras actividades diarias para un número notable de la población mundial. Sin esto, las gestiones de la COVID-19 se reducen a medidas particulares y acaso reprobables, que es lo que estos autores intentan enfatizar en el debate. Lo que pasan por alto así es que la «nueva normalidad» derivada de este despliegue revela unos intereses económicos, con sus medios y fines, y, en concreto, de clase.

Junto con lo que se ha popularizado como «nueva normalidad», las gestiones de la COVID-19 han confirmado la realización de un paradigma tecnoeconómico. Los paradigmas de este tipo aparecen y se suceden por revoluciones. Según una de sus principales teóricas, Carlota Pérez, son:

[...] a shared commonsense model of best technical and organizational practice for the use of that set of pervasive technologies which provides a generalized quantum jump in productivity and quality.

The techno-economic paradigm of each technological revolution defines the metaroutines for the whole economy. It provides the application models for the spread of the new generic technologies throughout the production landscape as well as the general principles guiding operations and even the search for new solutions, be they to fuel growth or to introduce incremental or radical innovation, be they for modernizing the established products, processes or industries or for creating novel ones. Each paradigm constitutes a new and universally applicable organizational logic for taking best advantage of the wealth-creating and modernizing potential that drives the whole Schumpeterian 'gale of creative destruction' (Pérez, 2007: 778). 
Un paradigma tecnoeconómico supone una revolución tecnológica. No surge de la nada, ni siquiera de una decisión, ya que una revolución de este tipo implica al menos dos factores. Primero, innovaciones tecnoeconómicas, combinaciones novedosas de productos preexistentes que acaban afectando a toda la economía (Schumpeter, 1964: 62-77). Un ejemplo actual es la IA. Como dice Harvey, el desarrollo y las aplicaciones de esta ya no solo se aplican a servicios rutinarios, como expedición de billetes de viaje o el paso por cajas de supermercado, sino a otros como la enseñanza superior, los diagnósticos médicos y el pilotaje aéreo (Harvey, 2014: 13). Segundo, las relaciones económicas por las que emerge una tecnología y respecto a las cuales es innovadora y genera un nuevo sentido común cuya proyección es paralela a la del paradigma en cuestión. El resultante es la constancia de lo que Schumpeter llamó «destrucción creadora» (Schumpeter, 2003: 83). Esta relativiza todo presunto destino, sea biopolítico o psicopolítico.

Harvey entiende el neoliberalismo como una manifestación histórica de la destrucción creadora. Lo reconoce también en China a partir de Deng Xiaoping y data su origen en unas fechas en que Pérez señala la aparición del paradigma tecnoeconómico vigente (Harvey, 2007a; Harvey, 2007b: 6-7; Pérez, 2007: 781). La prueba empírica de cualquier paradigma tecnoeconómico son saberes y poderes disruptivos, efectivos y de carácter tecnológico que configuran e individúan una sociedad radicalmente histórica. Por lo demás, tanto el paradigma vigente como la neoliberalización de la que habla Harvey parecen estar en la base de las gestiones de la COVID-19 en oposición a lecturas decisionistas como las de Agamben y Han.

Los paradigmas tecnoeconómicos son políticamente ambiguos dada la necesaria especificidad de las técnicas y tendencias que las posibilitan y generan. Son liberadores, pero no en abstracto ni de forma absoluta: liberan colectivos de ciertos trabajos y penurias, aunque nutriendo contradicciones genuinamente capitalistas y generando nuevos conflictos con sus respectivas luchas. ${ }^{4}$ Por eso, tales paradigmas no son estáticos ni meros comodines o instrumentos.

Un cambio de paradigma tecnoeconómico es transcendental porque modifica la tecnología general que subyace a todo el sistema productivo, como sucedió por ejemplo con la máquina de vapor o el ordenador. [...] Tales mudanzas en la tecnología básica tienden a modificar las cadenas de valor en prácticamente todas las ramas de la industria

\footnotetext{
$4 \quad$ Para una exposición pormenorizada y actualizada de dichas contradicciones, véase Harvey, 2014 y 2021.
} 
[...]. Tales innovaciones dan lugar a lo que Schumpeter llamaba «destrucción creativa»: aparecen nuevos sectores industriales con montones de nuevos productos, mientras que los viejos desaparecen debido a una pauta de demanda totalmente nueva, y se producen cambios radicales en los procesos de producción de casi todos los sectores. [...] Como señala Carlota Pérez, tales cambios tecnológicos radicales aportan cambios en el «sentido común». Poco después de que hombres y mujeres dejaran de trabajar en casa para acudir a trabajar en enormes fábricas, la actitud hacia los cuidados sanitarios cambió radicalmente. Ya no nacíamos, nos curábamos de las enfermedades y nos moríamos en casa, sino que hospitales parecidos a las grandes fábricas se hacían cargo de esas tareas (Reinert, 2007: 126).

Todo paradigma tecnoeconómico genera imaginarios ligados a las tecnologías predominantes. Da plena forma a la destrucción creadora y sintetiza las maneras hegemónicas de pensar y hacer de una sociedad capitalista, incluyendo sus fronteras.

No hay una historización estándar sobre los paradigmas tecnoeconómicos. Si atendemos a sus teóricos, se ha dicho que ha habido cinco grandes paradigmas de este tipo y que cada uno remite a una era compleja, en absoluto armónica o lineal, marcada por las innovaciones que han caracterizado una tecnología predominante. El primero se inicia con la revolución industrial británica; el segundo, con la era del vapor y el ferrocarril; el tercero, con la era del acero, la electricidad y la ingeniería pesada; el cuarto, con la era del petróleo, el automóvil y la producción en masa; y, el quinto, con la era de la informática y las telecomunicaciones (Freeman, 2004: 245; Freeman y Louçã, 2002; Pérez, 2002: 18; Pérez, 2007: 778-781; Reinert, 2007: 128; Reinert, 2009: 354). En este, el vigente, se da la irrupción de la IA y el big data, así como de las tecnologías y las plataformas digitales, incluyendo las redes sociales que hacen globalmente efectivas lo que Han llama el mandato de la transparencia, y el auge de la clase capitalista de los gigantes tecnológicos.

Se pueden inferir dos ideas generales de lo comentado en este apartado. La primera es que lo que las gestiones de la COVID-19 han mostrado no son solo nuevas decisiones, más o menos fantasmagóricas y unidireccionales, que vayan a marcar el futuro de la soberanía. Por el contrario, hay que entenderlas como la realización especial de un paradigma tecnoeconómico previamente existente que ha arraigado con el neoliberalismo desde tiempos de Reagan, Thatcher y Deng. La segunda es que el futuro del poder soberano, así como de los saberes técnicos, no va a depender de dispositivos generados por una serie de decisiones, se remonten estas a la Italia del siglo XVI o a la China actual. 
Dependerá, más bien, del incierto, conflictivo y político desarrollo de la economía existente, enmarcada en un paradigma concreto. Argumentaré estas ideas a continuación como antesala a una reflexión sobre el porvenir de la democracia.

\section{EL PORVENIR DE LA DEMOCRACIA}

La bioseguridad y la desaparición de tradiciones, la vigilancia exhaustiva y la excesiva confianza en una ciencia orientada a intervenir y producir, así como la generalización de la nuda vida y el trance de la democracia liberal, están siendo efectuadas con el último paradigma tecnoeconómico. Este no solo ha posibilitado las gestiones de la crisis provocada por la COVID-19, sino que puede ser estudiado en su desarrollo y aplicación, además de ser transversal y constitutivo de las nuevas enfermedades y soberanías tal como las presenta Han. Y lo que Agamben entiende como un perpetuo estado de excepción parece potenciado por las nuevas tecnologías en tanto que susceptibles de controlar y registrar todos nuestros movimientos.

Este paradigma ha posibilitado el teletrabajo y la educación, el consumo y el ocio online a gran escala, así como la información efectiva relativa a la pandemia, la cual va desde recomendaciones, restricciones y atenciones diversas a ordenar hobbesianamente el miedo, como denuncia Agamben. Pese a que el coronavirus haya arrebatado y alterado millones de vidas, con las consiguientes medidas biopolíticas y psicopolíticas, la nueva clase capitalista de los gigantes tecnológicos ha resultado enormemente beneficiada. Por ejemplo, Amazon llegó a facturar 13 ooo millones de dólares estadounidenses en solo un día al inicio de la pandemia (Blakeley, 2020). Estos acontecimientos comportan un uso progresivo de la IA en la economía: desde el cálculo de preferencias de cada consumidor y el archivo personalizado de los movimientos en la red hasta la predisposición de actos y deseos. Esto ya ocurre y no hay democratización a la vista.

En el ámbito global, está habiendo una creciente digitalización y vigilancia, las cuales se están llevando a cabo como dos caras de un mismo fenómeno. Esto se constata en transacciones, comunicaciones e incluso entretenimientos banales, con un claro impulsor en China (Andersen, 2020; Castillo, 2019). Pero no es que este país vaya a dictar o vender el futuro poder soberano global sin más, como dice Han, sino que el futuro de la soberanía no se entiende sin las 
TIC. Casos como los de Aaron Swartz, Julian Assange o Peter Snowden muestran que dicho fenómeno cuenta con rebeldes y mártires desde hace años. Contraponer modelo europeo y modelo asiático es sugerente, pero insuficiente. Al menos porque parece hacer abstracción de los intereses que salen fortalecidos y de cómo se protegen con el desarrollo del paradigma tecnoeconómico vigente.

Un porvenir para la democracia menos pesimista que el presentado por Agamben y Han puede ser pensado a partir de Stiglitz. Si bien es un defensor de la democracia liberal y del desarrollo tecnológico, a la par que sugiere que la riqueza y el progreso son prácticamente una consecuencia de la irrupción de los paradigmas tecnoeconómicos (Stiglitz y Greenwald, 2016: 37-38), se ha mostrado siempre muy crítico con las condiciones políticas y sociales derivadas del paradigma que ha hecho posible la «nueva normalidad». En su último libro (Stiglitz, 2020a) no solo reconoce que hay una nueva clase capitalista correlativa a dicho paradigma, sino que esta es actualmente un peligro para las sociedades democráticas.

Stiglitz dice que el capitalismo advenido con el último paradigma rompe las reglas capitalistas. Esto se ve en cómo los gigantes tecnológicos manipulan gravemente los precios de las mercancías en función de la información personalizada de los consumidores que obtienen desde las TIC (Stiglitz, 2020a: 174175). De ahí que, para él, haga falta un Gobierno comprometido con el rule of law y los valores ilustrados. 5 De hecho, lleva años denunciando que ahora los enemigos reales del capitalismo son los propios capitalistas, quienes, especialmente tras la crisis del 2008, han puesto los poderes estatales a su servicio en lo que llama asistencialismo corporativo (Stiglitz, 2015: 13). Antes de que se declarara la pandemia, acercándose a Agamben y Han, subrayó que, en la actualidad, el paso del autoritarismo al totalitarismo depende en parte de las TIC (Stiglitz, 2020a: 178). Esto implica una transformación de la privacidad, de las fronteras, de los malestares y, por supuesto, del poder soberano.

En el verano del 2020, ante las perspectivas de nuevos brotes de COVID-19 a lo ancho del globo, Stiglitz se pronunció públicamente para advertir de las terribles expectativas económicas y reafirmar su postura keynesiana (Stiglitz, 202ob).

\footnotetext{
He comentado críticamente esta propuesta en Morro, 2020.
} 
Otra propuesta menos pesimista para pensar el porvenir de la democracia la encontramos en Harvey. No hace mucho señalaba que la principal contradicción capitalista que se ha intentado responder desde el marxismo es la habida entre las posibilidades productivas de las tecnologías y la incapacidad de quienes las atesoran y explotan para ponerlas al servicio del bien común (Harvey, 2014: 101). También subrayaba que la contradicción es aún más explícita con la automatización y la IA, dado que parecen liberar de las tareas económicas más engorrosas (Harvey, 2014: 205, 211). La razón por la que esta contradicción persiste es su carácter de clase.

La clase capitalista, a diferencia del ejército, la burocracia o los científicos, busca el beneficio privado. Es su razón de ser. En esto coincide con Stiglitz, pero discrepa de este al señalar que la relación de esta clase con la tecnología, a la que Harvey define como «el uso de procesos y objetos naturales para obtener productos que satisfagan las necesidades o los proyectos humanos» (Harvey, 2014: 101), consiste en adaptarla y difundirla para obtener beneficios, por lo que no le resulta algo inherente como clase. La tecnología es algo que los capitalistas se apropian. Asimismo, afirma que el dinero, la banca, el sistema de crédito y el mercado son, hoy por hoy, tecnologías. Pero no son dispositivos en el sentido foucaultiano, porque remiten a procesos ejecutados al servicio una clase concreta y no arraigan sin estrategas. Además, no reproducen un poder, tampoco una metafísica o una decisión política, sino que dependen de complejas innovaciones que conducen a crisis y son irreductibles a maniqueísmos al uso.

Las contradicciones del capital han generado a menudo innovaciones, muchas de las cuales han mejorado la calidad de la vida cotidiana. Cuando las contradicciones dan lugar a una crisis del capital, propician momentos de «destrucción creativa». Rara vez sucede que lo que se crea y lo que se destruye esté predeterminado y menos aún que todo lo que se crea sea malo y todo lo que era bueno resulte destruido, y rara vez se resuelven totalmente las contradicciones (Harvey, 2014: 19).

Harvey remarca que las innovaciones aportan ventajas competitivas a las empresas, lo que permite entender por qué la «nueva normalidad» no solo confirma un paradigma tecnoeconómico preexistente: también hace más poderosa a quien monopoliza sus productos, jerarquizando férreamente incluso a los capitalistas. En relación con esto, siguiendo una filosofía de la historia alternativa a la de los enfoques biopolíticos y psicopolíticos, recuerda que las 
grandes empresas luchan entre sí. A esto hay que añadir que no existe el poder, unido, pero tampoco la clase capitalista unida. También los gigantes tecnológicos compiten por el mercado. No solo en un mercado, como dice Stiglitz, sino que su lucha comporta una mercantilización estratégica y creciente de acuerdo con la proyección diseñada de maximización de beneficio.

Los capitalistas apuestan por el monopolio en cuanto pueden (Harvey 2014: 102-103). No arriesgan, no van a competir deportivamente, y son conscientes de ello. Usan los medios posibles para mantener su ventaja, aunque sea desproporcionada hasta tal punto que impida un mercado libre y en condiciones más o menos equitativas. Esto, que es lo que lleva a Stiglitz a denunciar el asistencialismo corporativo, es entendido por Harvey como una tendencia inherente a la gran empresa capitalista. Ya Schumpeter denunció en la década de 1930 que la competencia es una ficción de los manuales de economía (Schumpeter, 2003: 84-85) y que la muerte natural de este tipo de empresas radica en no poder mantener el ritmo de innovaciones que exige un monopolio capitalista (Schumpeter, 1964: 68-72). Siguiendo esta idea, así como asumiendo el despliegue efectivo de los gigantes tecnológicos, Harvey sostiene que el deseo de innovación de los grandes monopolios de base siliconiana actualmente se proyecta como garante de los monopolios realmente existentes. Hoy, dado el poder de la nueva clase capitalista mediante las TIC, el cual se ha confirmado con las gestiones de la COVID-19, innovar parece tender a administrar lo existente.

Con la «nueva normalidad», al menos en Occidente, monopolios como los mencionados consolidan la posibilidad de un capitalismo administrado (Morro, 2017). Sin obviar el estado de excepción, sino más bien al contrario, este se construye sobre una particular gestión de lo dado. Su principal característica no es un «control por el control», como sugieren Agamben y Han, sino un control de vanguardia al servicio de una cada vez más restringida clase capitalista que, naturalmente, aspira al «control para el beneficio». De ahí que este paradigma tecnoeconómico se esté realizando con una severa crueldad, que responde a lo que Harvey denuncia como moderna razón económica (Harvey, 2019). No obstante, quizás sea más preciso llamarla razón tecnoeconómica. Y es que, con la «nueva normalidad», no solo se prevé un brutal aumento de gente prescindible para el gran capital, como dice Harvey, sino que se tenderá a prescindir de quien no se adapte a las condiciones del paradigma tecnoeconómico vigente. En este predominan las innovaciones en torno a la informáti- 
ca y las telecomunicaciones y, en consecuencia, como dice Han, la comunicación sin comunidad (Han, 202ob). Las gestiones de la COVID-19, que han potenciado tanto el distanciamiento social como la interacción digital, todo ello afectando a qué cabe entender por frontera, son un ejemplo.

Harvey ha anunciado una nueva clase trabajadora. Que lo económico, lo social y la vida están conectados y subordinados a intereses que desbordan lo personal se advierte al contrastar quién tiene permiso para ponerse en cuarentena, con o sin salario, y quién puede permitírsela en caso de contagio. Con Stiglitz coincide en que las consecuencias serán terribles para la inmensa mayoría y que esto no se deberá tanto al coronavirus en abstracto cuanto a cuatro décadas de neoliberalismo. Pero, a su juicio, la solución no pasa por un Gobierno que garantice la equidad, sino por una respuesta anticapitalista y no tecnofóbica. Deberán redefinirse los intereses a los que sirven las TIC. Y advierte: salvar la economía tras la pandemia, la cual «ha sumido al mundo en la peor crisis económica de la historia del capital», ha de conducir al socialismo (Harvey, 2020; Harvey, 2021: 105). Acaso sea la única alternativa efectiva a un capitalismo administrado.

Después de años en que se dice que la crisis del 2008 será como el crac del 29 y que nuestra época se parece a la década de 1930, aparte de tecnofilias y tecnofobias varias, no deberían extrañar las propuestas de inspiración keynesiana y marxiana tras las gestiones de la COVID-19. Menos si nos interesa el porvenir de la democracia. Y obviarlas no parece acorde con la actitud filosófica. Replanteando el debate iniciado por Agamben, ambas nutren argumentos frente a quienes optan por ver la pandemia como un simple problema científico con soluciones técnicas, banalizando así la política. Ahora bien, ninguna propuesta tendrá recorrido sin considerar las nuevas circunstancias derivadas de estas gestiones. Entre ellas, de acuerdo con Han, la mutabilidad de la soberanía, como intuyó Schmitt espantado por los desarrollos de un paradigma tecnoeconómico.

\section{BIBLIOGRAFÍA}

Agamben, Giorgio (1998). Homo Sacer. El poder soberano y la nuda vida. València: Pre-Textos. 
Agamben, Giorgio (2004). Estado de excepción. Homo Sacer II, 1. València: Pre-Textos.

Agamben, Giorgio (2011). ¿Qué es un dispositivo? Sociológica, 26(73), 249-264.

Agamben, Giorgio (2019). ¿Qué es real? Buenos Aires: Adriana Hidalgo. Agamben, Giorgio (2020a). ¿L'invenzione di un'epidemia? Quodlibet. Recuperado de: https://www.quodlibet.it/giorgio-agamben-1invenzione-di-un-epidemia [Consultado el 13 de junio de 2020]

Agamben, Giorgio (2020b). Contagio. Quodlibet. Recuperado de: https://www.quodlibet.it/giorgio-agamben-contagio [Consultado el 13 de junio de 2020]

Agamben, Giorgio (2020c). Chiarimenti. Quodlibet. Recuperado de: https://www.quodlibet.it/giorgio-agamben-chiarimenti

[Consultado el 13 de junio de 2020]

Agamben, Giorgio (2020d). Riflessioni sulla peste. Quodlibet.

Recuperado de: https://www.quodlibet.it/giorgio-agambenriflessioni-sulla-peste [Consultado el 13 de junio de 2020]

Agamben, Giorgio (2020e). Una domanda. Quodlibet. Recuperado de: https://www.quodlibet.it/giorgio-agamben-una-domanda [Consultado el 15 de junio de 2020]

Agamben, Giorgio (2020f). Nuove riflessioni. Quodlibet. Recuperado de: https://www.quodlibet.it/giorgio-agamben-sul-vero-e-sul-falso [Consultado el 15 de junio de 2020]

Agamben, Giorgio (2020g). Sul vero e sul falso. Quodlibet. Recuperado de: https://www.quodlibet.it/giorgio-agamben-sul-vero-e-sul-falso [Consultado el 15 de junio de 2020]

Agamben, Giorgio (2020h). Biosicurezza e politica. Quodlibet. Recuperado de: https://www.quodlibet.it/giorgio-agambenbiosicurezza [Consultado el 15 de junio de 2020]

Andersen, Ross (2020). The panopticon is already here. The Atlantic. Recuperado de: https://www.theatlantic.com/magazine/archive/2020/o9/china-aisurveillance/614197/ [Consultado el 31 de julio de 2020] 
Balibar, Étienne (2008). Del Cosmopolitismo a la Cosmopolítica. Revista Internacional de Filosofía Política, 31, 85-100.

Blakeley, Grace (2020). Why the Superrich Keep Getting Richer. Recuperado de: https://www.jacobinmag.com/2020/o7/superrichamazon-jeff-bezos-trillionaire [Consultado el 26 de julio de 2020]

Callaway, Ellen (2020). Should scientist infect healthy people with the coronavirus to test vaccines? Nature, $580(17)$. doi: $10.1038 / \mathrm{d}_{415} 86-$ o20-00927-3

Castillo, Octavio (2019). China: a la vanguardia tecnológica. El Universal. Recuperado de: https://www.eluniversal.com.mx/techbit/china-la-vanguardiatecnologica [Consultado el 25 de marzo de 2020]

Freeman, Christopher (2004). Income inequality in changing technoeconomic paradigms. Reinert, Erik S. (Ed.). Globalization, Economic Development and Inequality. An alternative perspective (243-257). Cheltenham-Northampton: Edward Elgar.

Freeman, Christopher y Louçã, Francisco (2002). As time goes by. From the Industrial Revolutions to the Information Revolution. Oxford-New York: Oxford University Press.

Han, Byung-Chul (2013). La sociedad de la transparencia. Barcelona: Herder.

Han, Byung-Chul (2014a). En el enjambre. Barcelona: Herder.

Han, Byung-Chul (2014b). Psicopolítica. Neoliberalismo y nuevas técnicas de poder. Barcelona: Herder.

Han, Byung-Chul (2015). La societat del cansament. Barcelona: Herder.

Han, Byung-Chul (2020a). La emergencia viral y el mundo de mañana. El País. Recuperado de: https://elpais.com/ideas/2020-03-21/laemergencia-viral-y-el-mundo-de-manana-byung-chul-han-elfilosofo-surcoreano-que-piensa-desde-berlin.html [Consultado el 23 de marzo de 2020]

Han, Byung-Chul (2020b). La desaparición de los rituales. Barcelona: Herder. 
Harvey, David (2007a). Neoliberalism as Creative Destruction. The annals of the American academy of political and social science, 610(1), 21-44.

Harvey, David (2007b). Breve historia del neoliberalismo. Madrid: Akal.

Harvey, David (2014). Diecisiete contradicciones y el fin del capitalismo. Madrid: Traficantes de sueños.

Harvey, David (2019). Marx, El Capital y la locura de la razón económica. Madrid: Akal.

Harvey, David (2020). Anti-capitalist politics in the time of COVID-19. Recuperado de: http://davidharvey.org/2020/o3/anti-capitalistpolitics-in-the-time-of-covid-19/ [Consultado el 26 de julio de 2020]

Harvey, David (2021). Valor en movimiento. New Left Review, 126, 105125 .

Laval, Christian y Dardot, Pierre (2015). La nueva razón del mundo. Ensayo sobre la sociedad neoliberal. Barcelona: Gedisa.

Matos, Andityas y García Collado, Francis (2020). El virus como filosofía. La filosofía como virus. Barcelona: Bellaterra.

Morro, Joan (2014). L'avenir d'Europa. Una lectura des del "darrer" Balibar. Mayos, Gonçal y Morro, Joan (Eds.). Hi ha una nova política? (61-85). Barcelona: La Busca.

Morro, Joan (2017). La destrucció creativa i el futur del capitalisme. Capdevila, Pol y García Collado, Francis (Eds.). El futur a l'encreuada. Filosofia $i$ societat (159-178). Barcelona: Associació d'Estudis Filosòfics.

Morro, Joan (2020). ¿Puede moralizarse el capitalismo? Un comentario crítico a Stiglitz. Revista Enfoques, 18(33), 23-44. Recuperado de: http://www.revistaenfoques.cl/index.php/revistauno/article/view/533 [Consultado el 8 de mayo de 2021]

Pérez, Carlota (2002). Technological Revolutions and Financial Capital; the Dynamics of Bubbles and Golden Ages. CheltenhamNorthampton: Edward Elgar. 
Pérez, Carlota (2007). Finance and technical change: a long-term view. Hanusch, Horst y Pyka, Andreas (Eds.). Elgar Companion to neoSchumpeterian economics (775-799). Cheltenham-Northampton: Edward Elgar.

Reinert, Erik S. (2007). La globalización de la pobreza. Cómo se enriquecen los países ricos... y por qué los países pobres siguen siendo pobres. Barcelona: Crítica.

Reinert, Erik S. (2009). Production-based Economic Theory and the Stages of Economic Development: From Tacitus to Carlota Perez. Dreschler, Wolfgang, Kattel, Rainer y Reinert, Erik S. (Eds.). Techno-economic paradigms: Essays in honour of Carlota Perez (333372). London-New York-New Delhi: Anthem Press.

Schmitt, Carl (2001). Teología política I. Cuatro capítulos sobre la teoría de la soberanía. En Orestes Aguilar, Héctor. Carl Schmitt, teólogo de la política. (19-62). México DF: FCE.

Schumpeter, Joseph A. (1964). Business Cycles. A Theoretical, Historical and Statistical Analysis of the Capitalist Process. Philadelphia: Porcupine Press.

Schumpeter, Joseph A. (2003). Capitalism, Socialism and Democracy. London-New York: Routledge.

Stiglitz, Joseph E. (2015). Prólogo. Schumpeter, Joseph A. Capitalismo, socialismo y democracia. Vol. 1. (11-19). Barcelona: Página indómita.

Stiglitz, Joseph E. (2019). The End of Neoliberalism and the Rebirth of History. Recuperado de: https:/www.projectsyndicate.org/commentary/end-of-neoliberalism-unfetteredmarkets-fail-by-joseph-e-stiglitz-2019-11?barrier=accesspaylog [Consultado el 26 de julio de 2020]

Stiglitz, Joseph E. (2020a). Capitalismo progresista. La respuesta a la era del malestar. Barcelona: Taurus.

Stiglitz, Joseph E. (2020b). Priorities for the COVID-19 Economy. Recuperado de: https:/www.projectsyndicate.org/commentary/covid-2O2O-recession-how-to-respondby-joseph-e-stiglitz-2020-06 [Consultado el 3 de julio de 2020] 
Stiglitz, Joseph E. y Greenwald, Bruce C. (2016). La creación de una sociedad del aprendizaje. Una nueva aproximación al crecimiento, el desarrollo y el progreso social. Madrid: La esfera de los libros.

WHO (World Health Organization) (2020). Clinical management of COVID-19: interim guidance. 27 May 2020. No. WHO/2019$\mathrm{nCoV} /$ clinical/2020.5.

Zolo, Danilo (1994). Democracia y complejidad. Un enfoque realista. Buenos Aires: Nueva Visión.

Zolo, Danilo (200o). Cosmópolis. Perspectivas y riesgos de un gobierno mundial. Barcelona: Paidós. 